This item was submitted to Loughborough's Institutional Repository (https://dspace.lboro.ac.uk/) by the author and is made available under the following Creative Commons Licence conditions.

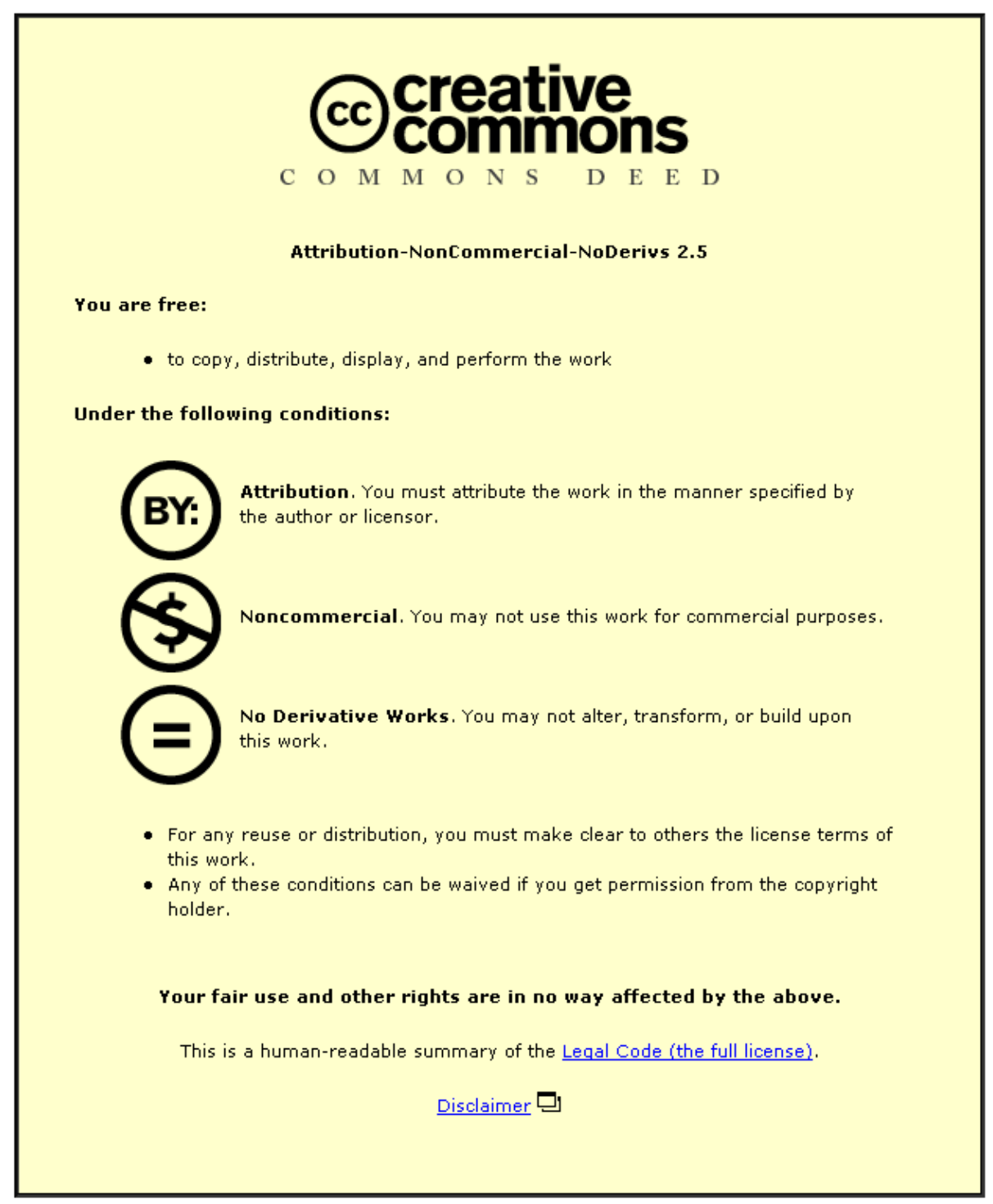

For the full text of this licence, please go to: http://creativecommons.org/licenses/by-nc-nd/2.5/ 


\title{
Business Performance Measurement Practices in Construction Engineering Organisations
}

\author{
Dr Herbert S. Robinson BSc (Hons), MIP, PhD \\ Prof. Chimay J. Anumba BSc (Hons), PhD, CEng, FICE, FIStructE, FCIOB, MASCE \\ Dr Patricia M. Carrillo BSc (Hons), MSc, PhD, FCIOB, MICE, CEng \\ Dr Ahmed M. Al-Ghassani BEng, MSc, PhD, MASCE
}

\author{
Department of Civil and Building Engineering \\ Loughborough University \\ Loughborough \\ Leicestershire LE 11 3TU, UK
}

Dr Herbert Robinson is a Senior Research Associate at Loughborough University. His industrial experience includes working on major construction projects at Ove Arup (UK) and a World Bank funded Project in The Gambia. His current research interests focus on knowledge management, business performance improvement and privately financed infrastructure projects.

Professor Chimay Anumba holds the chair in Construction Informatics and he is the founding Director of the Centre for Innovative Construction Engineering at Loughborough University. His industrial experience spans over 14 years. He has recently held the post of Visiting Professor at the Massachusetts Institute of Technology (MIT) and Stanford University.

Dr Patricia Carrillo is a Senior Lecturer in Construction Management in the Department of Civil and Building at Loughborough University, UK and Visiting Professor at the University of Calgary, Canada. She has worked in industry and her research interests focus on knowledge management, business performance, mergers and acquisitions, and strategic management.

Dr Ahmed Al-Ghassani is a lecturer at the Construction Department in Salalah College of Technology in Oman. Prior to that, he worked for Dhofar Municipality, in Oman, on several prestigious projects. His research interests include improving the process of structural design, using information technology (IT) and knowledge management (KM) in construction.

\section{$\underline{\text { Author for Correspondence }}$}

Dr Herbert Robinson

Department of Civil and Building Engineering,

Loughborough University,

Loughborough, Leicestershire LE 11 3TU, UK

E-Mail: h.s.robinson@ lboro.ac.uk

Phone: +44 (0) 1509263171 Ext. 4140

Fax: +44 (0) 1509223981 


\begin{abstract}
Performance improvement has been the subject of recent initiatives in the UK construction industry as a result of complex internal and external factors. These include demands from clients, investors and stakeholders for improvement and changes in market conditions. The need for performance improvement has led to the implementation of industry-specific key performance indicators (KPIs) and greater awareness of the benefits of measurement in construction engineering organisations. This paper presents and discusses findings based on the practical experiences of leading construction engineering organisations in the UK. A significant proportion of organisations are now using a range of financial and non-financial measures to assess business performance, and a growing number are adopting the Excellence Model and the Balanced Scorecard to facilitate a structured approach to implementing continuous improvement strategies. The paper concludes with some practical considerations for implementing performance measurement models.
\end{abstract}

Keywords: Performance measurement, Excellence Model, Balanced Scorecard, Construction Organisations 


\section{INTRODUCTION}

Performance improvement has been the subject of recent studies and initiatives in the UK construction industry as a result of complex internal and external factors (Latham, 1994; Egan, 1998). Clients, investors and other stakeholders are demanding continuous improvement. The increased reliance on industry-specific key performance indicators (KPIs) particularly in large organisations is a reflection of the growing importance of performance measurement. It is also recognition that industry performance should be judged not only on financial information, as this is no longer sufficient for understanding the dynamic business environment. The dominance of financial measures are due to traditional accounting practices with emphasis on shortterm indicators such as profit, turnover, quarterly earnings, cash flow and share prices. There is growing evidence that non-financial measures are becoming important to organisations, their clients, investors, and stakeholders. Demand for changes in corporate reporting are also likely to force organisations to adopt a more balanced approach to performance measurement.

A balanced approach is essential in identifying areas for improvement and facilitating continuous improvement. However, continuous improvement cannot be adequately monitored unless it is measured as 'what gets measured gets attention, particularly when rewards are tied to the measures' (Eccles, 1991). Measurement, is therefore, an integral part of business improvement as it is often seen as the information system at the heart of the performance management process (Kagioglou et al, 2001). 
Following the Egan (1998) report on "Rethinking Construction" in the UK, a significant interest has been generated in measuring the performance of construction organisations using so-called Egan key performance indicators (KPIs). KPIs mainly incorporate project and related measures to identify areas for improvement and to facilitate benchmarking against best practices. (Department of the Environment, Transport and the Regions, 2000). However, awareness of the use of other measurement systems such as the Balanced Scorecard (Kaplan and Norton, 1996) and the Excellence Model (EFQM, 1999) has increased in construction engineering organisations. The Balanced Scorecard, for example, allows managers to assess performance from four important perspectives; a customer perspective, financial perspective, internal business perspective and innovation and learning perspective. The Excellence Model encourages organisations to adopt a forward-looking perspective by focusing on a broad range of measures including processes, people, leadership, partnership and resources, products, society, learning and innovation. Both the Balanced Scorecard and the Excellence Model have been around for over 10 years but the take-up within construction organisations is slow (Watson and Seng, 2001).

Construction organisations have often been criticised for resistance to change and for failing to adopt innovative approaches to improve future business performance. This paper explores performance measurement and improvement practices in leading UK construction engineering organisations. It starts with an outline of the study objectives and methodology. The different performance measures and types of business performance measurement models applied are then examined and discussed. The paper concludes with practical considerations for implementing performance measurement models to facilitate business improvement. 


\section{STUDY OBJECTIVES AND METHODOLOGY}

The aim of the study was to assess current practices in business performance measurement in construction engineering organisations. A survey was conducted as part of a larger study investigating the relationship between knowledge management practices and business performance in major UK construction engineering organisations. The specific objectives of the study were as follows: (1) to examine attitudes and approaches to performance measurement and (2) to identify the types of performance measurement models in use, their benefits and the barriers to their widespread implementation. Initial discussions with the project's industrial partners provided the basis for identifying key themes on performance measurement. Telephone enquiries were made to establish contacts in engineering and construction organisations. A total of 170 questionnaires were sent to the leading construction engineering firms. These organisations are considered to be the most influential in the UK construction sector. A total of 53 completed questionnaires were received giving a response rate of $31.2 \%$. This is considered very good for a mail or postal questionnaire mainly due to the follow-up telephone contacts after the questionnaires were sent. Bourque and Fielder (1995) noted that a postal questionnaire without any incentive could probably expect no better than $20 \%$ response rate.

\section{RESULTS AND DISCUSSIONS}

About half of the responses are from construction contractors, $40 \%$ from engineering consulting organisations and the rest (less than 10\%) are from organisations with significant involvement in construction asset creation and management. Half of the organisations surveyed operate mainly in the UK market, while $43 \%$ are international 
companies with activities worldwide, and the rest are European-based. The organisations are grouped into three categories. Category III organisations are the largest with more than 1,500 employees. Category II organisations employ between 500 to 1500 staff, while category I organisations have less than 500 employees.

Figure 1 shows the distribution of respondents by size of organisations.

Take in Figure 1: Organisations by number of employees

\section{Attitude to Performance Measurement}

The range of measures used varies as different aspects of business performance are measured. Over $85 \%$ of the organisations use a combination of financial and nonfinancial measures. As expected, profit and turnover are identified as the key financial measures by almost all of the organisations. However, there is recognition that other measures particularly non-financial measures are becoming important. About half of the organisations use 'return on capital employed', $43 \%$ use 'sales' and $40 \%$ use 'return on investment' as measures of business performance. A third use the 'number of new customers' and a quarter use 'market share'. However, there are some differences between construction contractors and engineering consultants (see Table I).

Take in Table I: Financial and related measures by type of organisation

\section{Impact of Organisational Size on Measurement Practices}

There are differences reflecting the size of organisations. A higher proportion of larger organisations uses financial and market-related measures compared to smaller organisations (see Figure 2).

Take in Figure 2: Financial and related measures by size of organisation 
About half of the larger organisations (category III) use market share as a performance measure compared to about $15 \%$ for category II and less than $10 \%$ for category I organisations. The significant relationship between the popularity of market share measures and the size of organisations is not surprising, given that 'market share' is a strategic tool for large organisations. This, in part, explains why merger and acquisition activities are more popular and significant at the top end of the construction market.

\section{Non-financial Measures}

While financial measures will continue to be a crucial aspect of corporate performance there is evidence that non-financial measures are becoming increasingly important for corporate sustainability. This is due, in part, to the growing interest from investors, clients and other stakeholders for non-financial information, but also the demand for changes in corporate reporting following recent high profile business failures (DiPiazza and Eccles, 2002). About 90\% of the respondent organisations measure aspects of customer characteristics such as customer satisfaction, expectation, complaint or after sales service. Two-thirds (66\%) of the respondents use measures to assess the impact of their business activities on society such as pollution, safety, accidents, and resource preservation. Sixty-four percent have measures for employees reflecting job satisfaction, working conditions and opportunities for learning and growth. Measurement of employees' characteristics is important as the quality of service offered by organisations depends on the expertise, training and ability of its staff. About $62.3 \%$ of organisations also have measures for product performance whilst $47.2 \%$ have measures for processes used to deliver services. The relatively low proportion of organisations using process measures generally reflects 
the difficulties in measuring diverse and often complex processes in construction and engineering activities.

\section{Impact of Business Activities on Measurement Practices}

There are differences between contractors and engineering consulting organisations. A significantly higher proportion of contractors uses measures for processes, products and impact on society when compared to consultants (see Table II).

Take in Table II: Non-financial measures by type of organisations

This is due mainly to the differences between the design activities carried out by consultants, and the construction activities of contractors. Engineering design activities are complex, iterative and knowledge-intensive (Kumar and Topping, 1991). It requires a high level of tacit knowledge and creativity that could be stifled by the introduction of too many process measurement points. The end products and impact on society are also different. The end product of construction is a building or structure, more tangible and highly visible. In contrast, the end product of design is often perceived to be less tangible and visible. Measures on society are considered more important from a contractor's perspective as construction activities are sitebased and affect the lives of communities during and after construction. The increased awareness in measuring the impact on society is in response not only to the need to minimise the environmental effects of construction activities but as part of a growing corporate sustainability agenda to give something positive back to society. 


\section{Impact of Organisational Size on Measurement Practices}

There are variations in measurement practices between various categories of organisations. For example, measuring processes and impact on society is more widely adopted by large organisations (see Figure 3).

Take in Figure 3: Non-financial measures by size of organisation

There are a number of reasons for this. Firstly, the increased merger and acquisition activities at the top end of the construction market have transformed many large organisations, and the implication is that some have inherited different processes to execute similar tasks. This makes the measurement of processes more crucial to streamline their activities and to determine the most effective approaches. Secondly, there is also an increased awareness by large organisations of the environmental and community responsibility in terms of the processes used and the impact of large scale and complex projects.

\section{Choice of Performance Measurement Model}

Over three-quarters $(77.4 \%)$ of organisations have a business performance measurement system, with up to $15 \%$ of the organisations using more than one system (See Figure 5). A third (34\%) of the organisations use some form of key performance indicators (KPIs). However, a growing number of organisations are adopting the Excellence Model and the Balanced Scorecard (BSC). Almost twice as many organisations (23\%) use the Excellence Model on its own compared to the Balanced Scorecard (13\%).

Take in Figure 4: Use of business performance measurement models 
About $86 \%$ of larger organisations (category III) use performance measurement models, compared to $72.2 \%$ of category II and $71.4 \%$ of category I organisations. Although the Excellence Model and Balanced Scorecard have been around for over 10 years, they have only recently been taken up in construction organisations (Watson and Seng, 2001). On average, the Excellence Model has been in use for a slightly longer period. (Two and three-quarter years compared to two and a half years for the Balanced Scorecard). There are also variations between organisations of various sizes. For example, for the Excellence Model, the average period of use is two and a half years for large organisations (category III), two and three-quarter years for category II and three years for category I. Also, twice as many category I organisations (60\%) have adopted the Excellence Model for at least three years compared to category III organisations (29\%). The situation is reversed for the Balanced Scorecard. Twice as many category III organisations $(50 \%)$ have adopted the Balanced Scorecard for at least three years compared to category I organisations (25\%).

Critics of the Balanced Scorecard often argue that it is a less structured/holistic tool considered to be only the 'Result side' of the Excellence Model. However, the result suggests that the Balanced Scorecard is more widely applied in larger organisations. A number of possible explanations could be given for this. Firstly, the Balanced Scorecard is internationally recognised and therefore more popular than the Excellence Model. Introducing new systems or ideas such as the Excellence Model tend to be fraught with difficulties in larger organisations as a result of complex cultural, human and organisational issues. Change management programmes often accompany new systems introduced, which needs time with significant personnel and resource implications. Thirdly, this could be primarily due to the measurement-based 
or simplicity of the Balanced Scorecard in relation to KPIs which most leading construction organisations are using. However, case studies ${ }^{1}$ have shown that there is a growing popularity in the application of the Excellence Model in UK construction engineering firms, although some have experimented, in varying degrees, with the Balanced Scorecard in the past. This popularity is due to a number of factors such the holistic nature of the model; relative ease of determining and monitoring associated indicators influence of clients, the robustness and clarity in understanding and linking enabling activities with results in the Excellence Model.

\section{Business Benefits}

Business performance measurement models facilitate continuous improvement. They provide a balance between short and long term objectives, financial and non-financial measures and external and internal performance. $17.4 \%$ rated the Excellence Model as very good, $43.5 \%$ (good) and the rest, $39.1 \%$ were unsure about the business benefits. The corresponding ratings for the Balanced Scorecard are 21.1\% (very good), $42.1 \%$ (good) and $36.8 \%$ (unsure). None of the organisations rated KPIs as very good, while $57.1 \%$ rated them as good, and $28.6 \%$ were unsure. The rest (about $14 \%$ ) rated them as poor as they provide only a limited scope for addressing improvement. KPIs rely mainly on (backward-looking) lagging indicators reflecting past performance rather than (forward-looking) proactive measures. In contrast, none of the organisations rated the Excellence Model or the Balanced Scorecard as poor. This is because they do not only incorporate measurement systems but are holistic frameworks that provide strategic direction and priorities, and more significantly, they provide mechanisms for implementing improvement initiatives.

\footnotetext{
${ }^{1}$ Citation to our own work/ publication to be included on completion of refereeing
} 
There are some variations between categories of organisations. About $43 \%$ of larger organisations (category III) rated the Balanced Scorecard as very good compared to $17 \%$ of smaller organisations (category I). The pattern is the same for the Excellence Model with $38 \%$ of larger organisations giving a rating of very good compared to $17 \%$ of smaller organisations (category I). The relatively higher ratings from large organisations, where there are diverse activities in different business units with sometimes conflicting goals and priorities, reflects the benefits of performance measurement models in providing a clear strategic direction and an informed approach to business improvement. It may also reflect the relative ease of implementation of such models in large organisations due to the resources provided, data availability and support structure.

\section{Barriers to Implementation}

The main barriers identified in the adoption of performance measurement models are:

- determining and monitoring indicators;

- lack of data;

- time, and

- financial resources.

Problems associated with determining and monitoring indicators include choosing the wrong measures not aligned to business objectives or relying on lagging measures reflecting past performance. Data problems relate to the process of collection, collation and standardisation. Differences were observed in terms of the barriers identified for the Balanced Scorecard and the Excellence Model. 
For the Balanced Scorecard, about $43.4 \%$ of organisations identified 'determining and monitoring indicators' as the most significant barrier. Other barriers include time (26.4\%), data $(24.5 \%)$ and financial resources (18.9\%). Determining and monitoring indicators was the most significant barrier (30.2\%) in the Excellence Model but this is considerably less than the $43.4 \%$ for the Balanced Scorecard. Other barriers identified are time (22.6\%), data (20.8\%) and financial resources (20.8\%). Although the rank order is the same, there are notable differences between different categories of organisations. For example, for the Balanced Scorecard, data problems appear to be more important to smaller organisations than time. All category I organisations rated data as an important barrier compared to about a third (33.7\%) for time. In contrast, larger organisations consider time as a more significant barrier than data. This is because larger organisations tend to benefit from membership of large networks created for sharing data or information, and benchmarking performance. For example, the Major Contractors Group (MCG) in the UK is a benchmarking club supported by large construction organisations. A number of benchmarking clubs has been created in construction and other sectors. Financial resources are considered more of a barrier to smaller organisations than larger ones. About half (50\%) of the smaller organisations (category I) rated it as very important, compared to $25 \%$ of category II and none of the larger organisations (category III).

However, when the level of significance (based on a rating scale) of the barriers is taken into account, differences emerge between the Balanced Scorecard and the Excellence Model. Figure 5 is a comparison of the barriers identified with respect to both models using a five-point rating scale from the least significant (1) to the most significant (5). 
Take in Figure 6: Barriers in implementing models

For the Balanced Scorecard 'determining and monitoring indicators' is considered significantly more important than data. In contrast, data is considered to be more of a significant barrier in the Excellence Model. The result suggests that although the Balanced Scorecard appears to be simpler, easier to use and understand, there are significant problems associated with determining and monitoring indicators. Critics of the Balanced Scorecard argued that it is a less structured measurement tool compared to the Excellence Model.

\section{KEY CONSIDERATIONS IN IMPLEMENTING MEASUREMENT MODELS}

Performance measurement models provide a strategic framework for identifying actions required and focuses on priorities to achieve business objectives. However, in implementing performance measurement models, a number of considerations should be addressed.

\section{Leadership and commitment}

Leadership and commitment are crucial in implementing performance measurement models. The Chief Executive Officer of one high tech company gave leadership for performance measurement models to the finance function due their experience but also to broaden their perspectives and measurement skills (Eccles, 1991). A similar approach was adopted recently by a leading construction organisation ${ }^{2}$. Others have appointed business, continuous improvement or quality managers to implement their performance measurement models. In some organisations, champions are appointed 
for each criterion in the performance measurement model. For example, in a leading consulting engineering firm, each Board member is responsible for a criterion in the Excellence Model. Whatever post is allocated the responsibility, it is important to be committed to an organisation's efforts on performance measurement.

\section{Performance measurement system}

Organisations are using various types of performance measurement models and some have adopted more than one measurement system. It was suggested that smaller companies aware of the importance of KPIs might find the Balanced Scorecard the more useful tool, due to its simplicity. However, there is 'still uncertainty as to whether the Balanced Scorecard is more strategic or more measurement-based with respect to the Excellence Model' (CIRIA, 2001). It is important to consider what business performance measurement models an organisation's clients are using. Whatever system is selected should inform management about areas for improvement.

The application of performance measurement models should reflect the way a business operates. Some organisations use a company-wide strategy whilst others implement performance measurement initially in business units or diagonally before being integrated into the whole company. The advantages of implementing it diagonally or by business units is that lessons learnt could be transferred, benefits could be demonstrated and resistance to change addressed before selling it to the entire company. Implementing it diagonally also provides the added advantage of reaching all levels with a limitation on the number of people involved at each level.

\footnotetext{
${ }^{2}$ Citation to our own work/ publication to be included on completion of refereeing
} 


\section{Choosing the right measures}

A major problem in implementation is how to devise and integrate a set of financial and non-financial measures to reflect an organisation's strategic objectives (Butler et $a l, 1997)$. A significant proportion of organisations now recognises the need for a balanced approach to performance measurement. The measures could reflect objectives at different tiers of an organisation (e.g. corporate, departmental, functional or project levels). Stewart (1997) outlined two criteria (1) choose measures which will allow management to evaluate year-to-year performance and (2) measures should permit company-to-company comparisons. Measures should also be smart - specific, measurable, attainable, relevant and timely (Hampshire, 1999).

\section{Understanding the purpose of measurement}

The purpose of measurement is to identify areas for business improvement. There is a need to understand the dynamic (cause and effect) relationships between non-financial and financial measures that drive improvement in business performance.

For example, Stewart (1997) explained that if you cannot demonstrate the link between increased customer satisfaction and improved financial results, you are not measuring customer satisfaction correctly. He further argued that "happy customers should exhibit at least one of three measurable characteristics: loyalty (retention rates) increased business (share-of-wallet) and insusceptibility to your rivals' blandishments (price tolerance)".

\section{Role of knowledge management}

Learning is an essential aspect of improvement and knowledge sharing an essential mechanism for facilitating continuous improvement. It is, therefore, important to 
recognise the role of knowledge management in underpinning a business improvement plan. Both the Balanced Scorecard and the Excellence Model are strategic tools with a learning and innovation dimension. However, the innovation and learning aspects although important are often overlooked. About $92 \%$ of organisations using the Balanced Scorecard or the Excellence Model have or plan to have a knowledge management strategy within the short term (see Table III). Of those organisations who have or plan to have a knowledge management strategy, about twothirds also use various measures for employees, as staff turnover is a crucial factor relating to knowledge retention and distribution.

\section{Managing change}

One of the weaknesses of performance measurement models is their inability to deal with the capability for change. Introducing new systems tends to be fraught with difficulties. People and organisations often find change difficult and there is sometimes resistance to adopting new ways of doing business. New systems introduced therefore need to be accompanied by a change management programme to address barriers relating to organisational culture, people, time, data, and resources. These issues are crucial to a successful implementation of business performance measurement models. 


\section{CONCLUSIONS}

Performance measurement systems provide a mechanism to focus on wider business performance measures, which enables organisations to implement business improvement. The drive for implementing performance measurement models is gaining momentum as a result of market conditions forcing organisations to change, clients, investors and other stakeholders demanding continuous improvement. A growing number of UK construction engineering organisations now recognise the importance of supplementing traditional financial measures with non-financial measures. A significant proportion of organisations are therefore adopting the Excellence Model and the Balanced Scorecard to implement business improvement strategies in a structured way. It is expected that more construction engineering organisations will use diverse performance measures and adopt performance measurement models as implementation barriers are gradually overcome and the benefits become clear.

\section{ACKNOWLEDGEMENT}

This paper is part of a major study sponsored by the UK Engineering and Physical Research Council (EPSRC) - Grant No. GR/N01330. The contributions of a number of industrial collaborators to the project are acknowledged. 


\section{REFERENCES}

Bourque, L.B. and Fielder, E. P. (1995), How to Conduct Self-Administered and Mail Surveys, SAGE Publications, California, USA.

Butler, A., Letza, S.R. and Neale, B. (1997), Linking the Balanced Scorecard to Strategy, Long Range Planning, Vol. 30, No 2, 242 -253.

CIRIA (2001), The Balanced Scorecard - The American Way, Members Report E1121, Report of a joint workshop of Construction Productivity Network and British Quality Foundation, Commonwealth Institute, London, $16^{\text {th }}$ May

Department of the Environment, Transport and the Regions (2000), KPI Report for the Ministry for Construction, The KPI Working Group, London, U.K

DiPiazza, S. A., (Jr) and Eccles, R. G. (2002), Building Public Trust: The Future of Corporate Reporting, John Wiley and Sons

Eccles, R. G. (1991), The Performance Measurement Manifesto, Harvard Business Review, January - February, 131-137.

EFQM (European Foundation for Quality Management), Introducing Excellence, Brussels, Belgium.

Egan, J. (1998), Rethinking Construction: Report of the Construction Task Force on the Scope for Improving the Quality and Efficiency of the UK Construction Industry, Department of the Environment, Transport and the Regions, London

Hampshire, J. (1999), The Logical Framework Approach Guidelines, Material prepared as part of AusAid's Project Management Guidelines.

Kagioglou, M., Cooper, R., Aouad, G. (2001), Performance Management in Construction: A Conceptual Framework, Construction Management and Economics, 19, 85-95 
Kaplan, R.S. and Norton, D. P. (1996), The Balanced Scorecard - Measures that Drive Performance, Harvard Business Review, 70(1), 71-79.

Kumar, B., and Topping, B.H.V (1991). "Knowledge-based Processing for Structural Design." Proceedings of the Institute of Civil Engineering, Part 1, Vol 90, April, $421-446$.

Latham, M. (1994), Constructing the Team, Joint Review of Procurement and Contractual Arrangements in the UK Construction Industry, London

Stewart, T.A. (1997) Intellectual Capital: The New Wealth of Nations, Doubleday, New York, USA.

Watson, P. and Seng, L.T (2001), Implementing the European Foundation for Quality Management Model in Construction, Construction Information Quarterly, Construction Paper 130, 1-8.

Whiting, E. (1986), A Guide to Business Performance Measurements, The Macmillan Press Ltd, Hampshire, UK. 
Figure 1: Organisations by number of employees

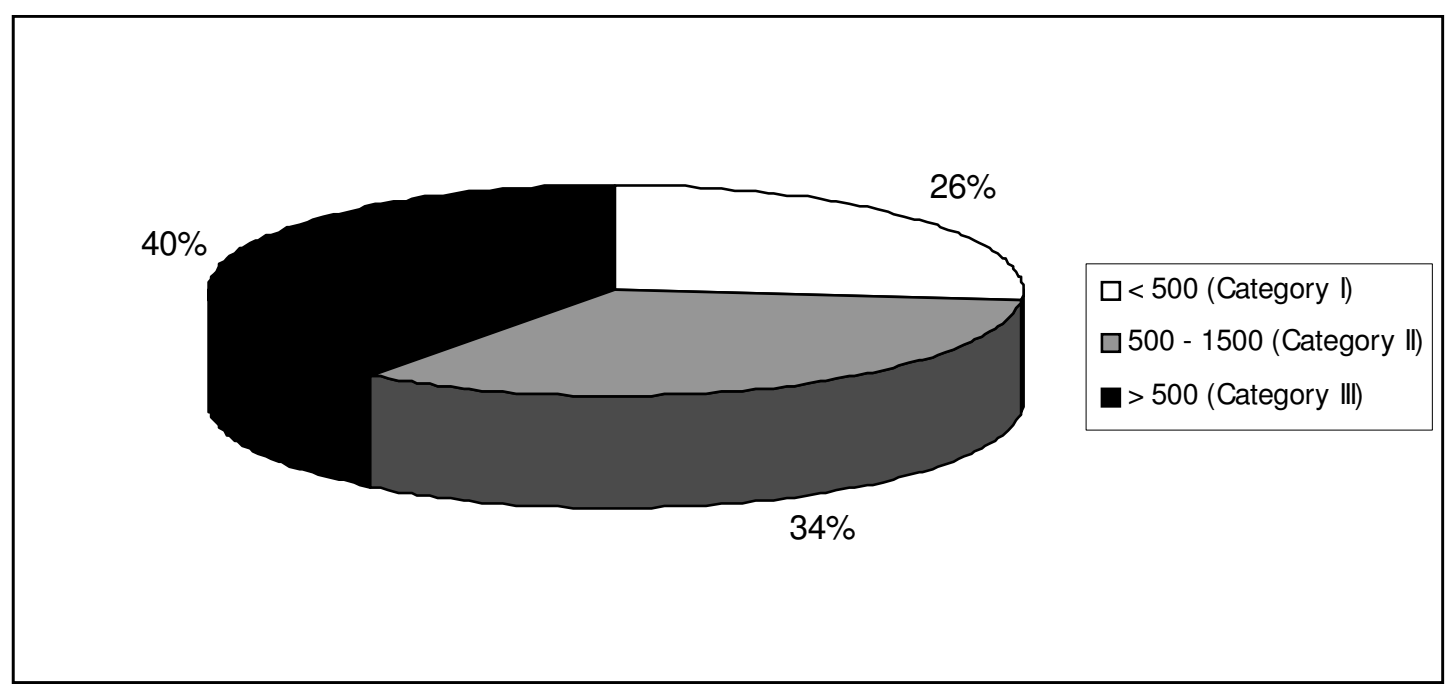


Figure 2: Financial and related measures by size of organisation

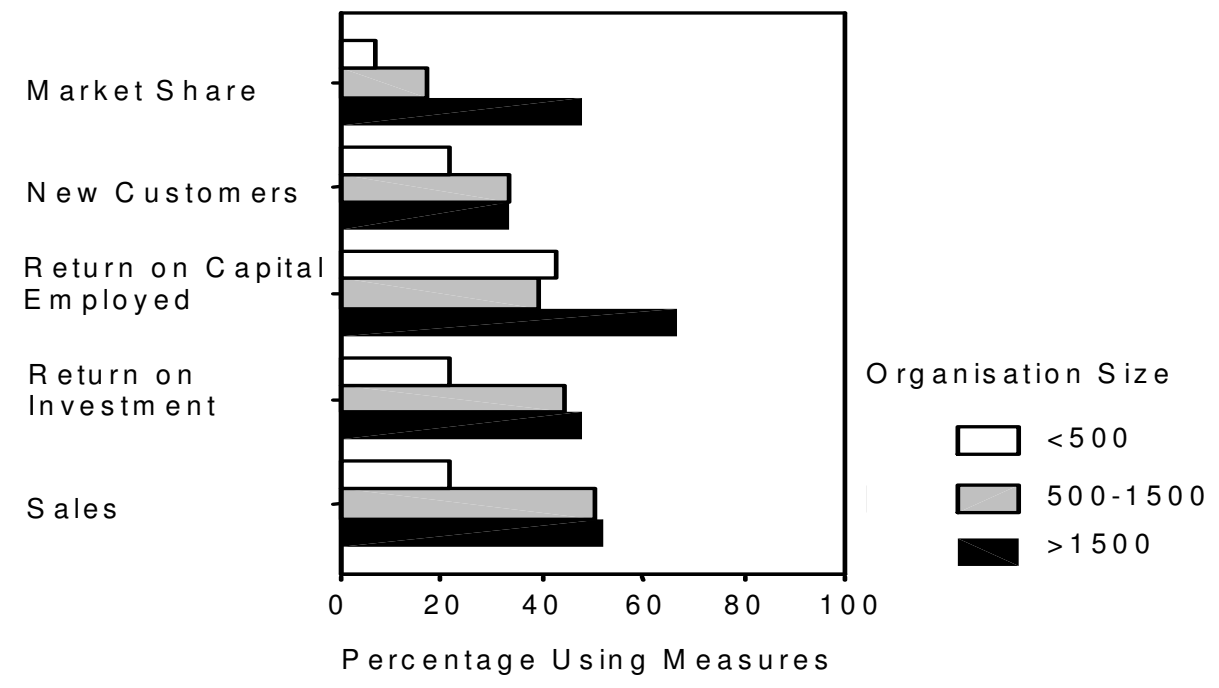


Figure 3: Non-financial measures by size of organisation

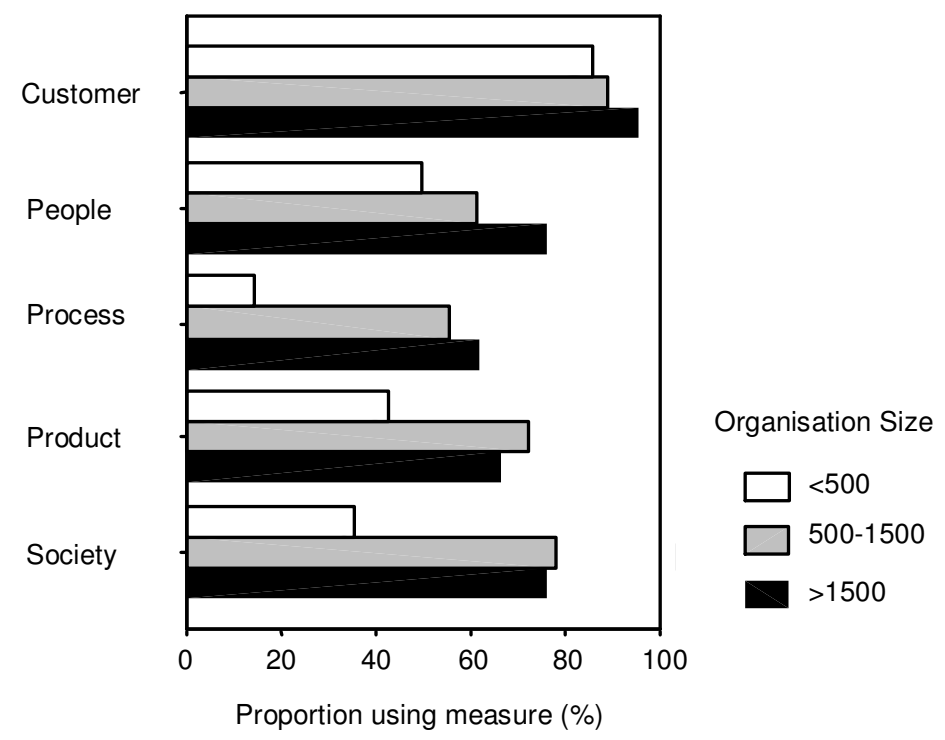


Figure 4: Use of Performance Measurement Models

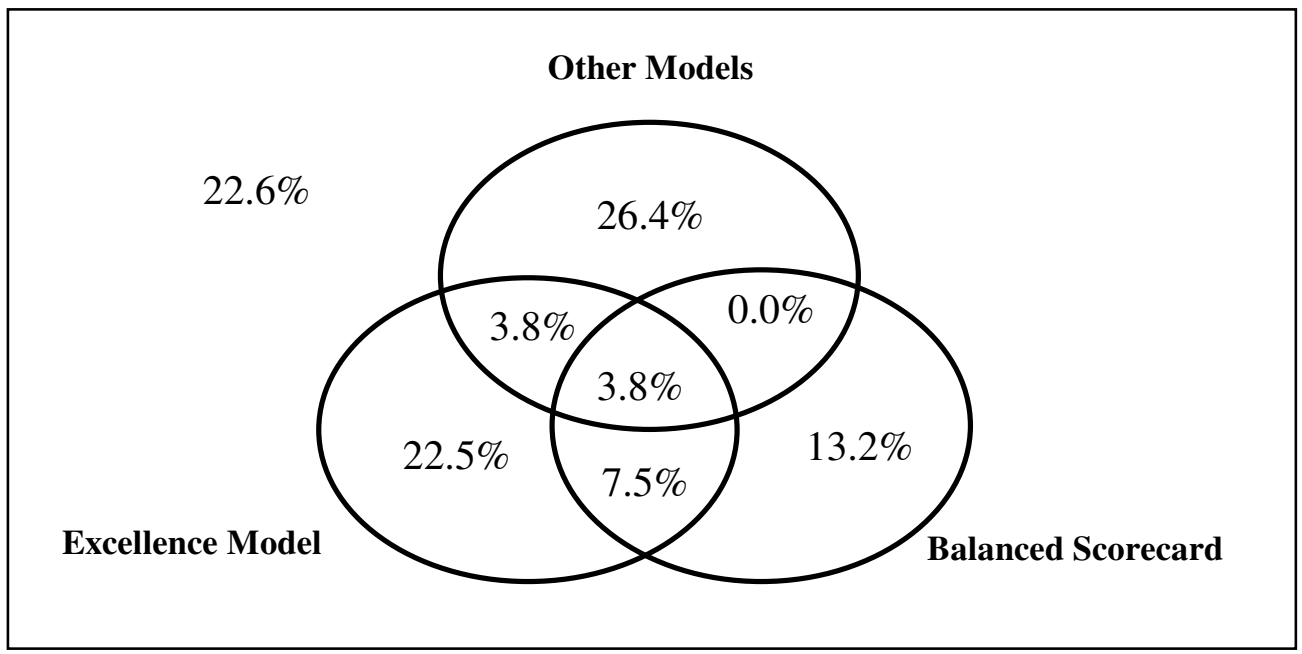


Figure 5: Barriers in Implementing Models

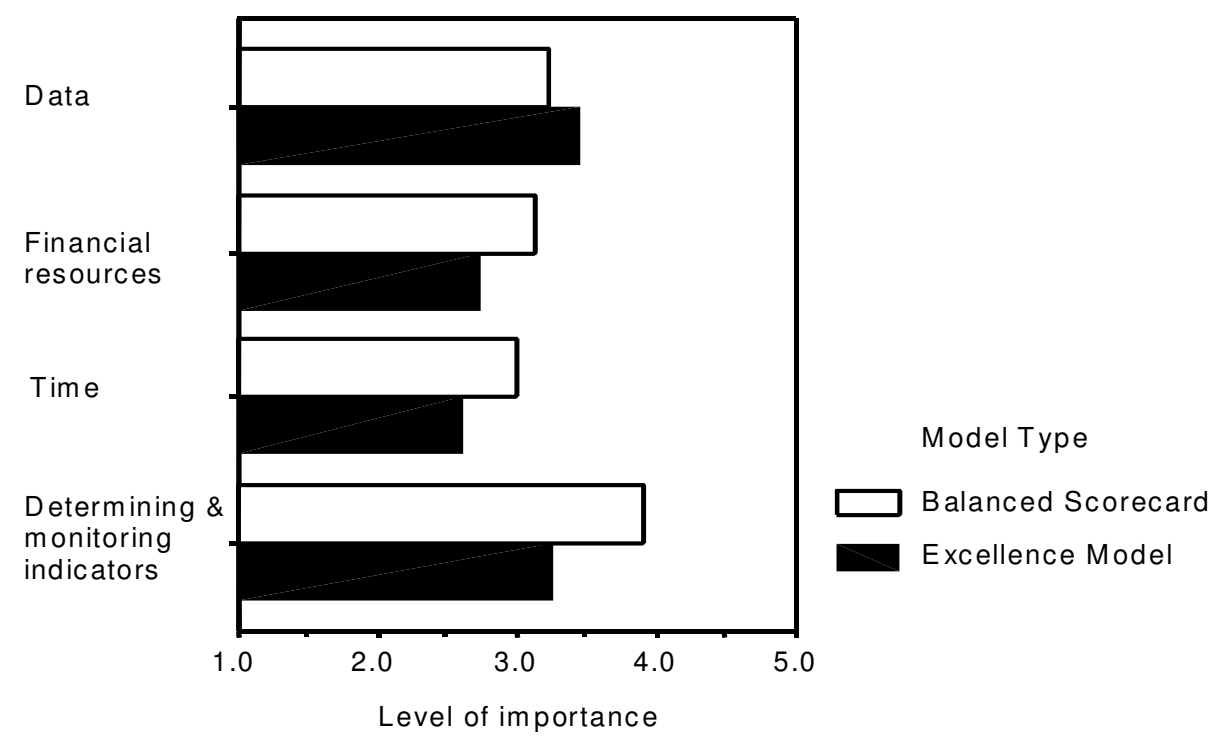


Table I: Financial and related measures by type of organisation

\begin{tabular}{|c|c|c|}
\hline \multirow{2}{*}{ Type of measure } & \multicolumn{2}{|c|}{ Type of Organisation } \\
\hline & Contractors & Consultants \\
\hline Market share & 29.6 & 23.8 \\
\hline New customers & 25.9 & 33.3 \\
\hline Return on capital employed/ & 59.3 & 42.9 \\
\hline Return on investment & 33.3 & 42.9 \\
\hline Return on capital employed & 59.3 & 42.9 \\
\hline Nos. of new customers & 25.9 & 33.3 \\
\hline Sales & 44.4 & 42.9 \\
\hline
\end{tabular}

Table II: Non-financial measures by type of organisation

\begin{tabular}{|c|c|c|}
\hline \multirow{2}{*}{ Type of measure } & \multicolumn{2}{|c|}{ Type of Organisation } \\
\hline & Contractors & Consultants \\
\hline Customer & 88.9 & 90.5 \\
\hline Process & 51.9 & 38.1 \\
\hline People & 63.0 & 61.9 \\
\hline Product & 77.8 & 42.9 \\
\hline Society & 77.8 & 52.4 \\
\hline
\end{tabular}

Table III: Performance measurement and knowledge management

\begin{tabular}{|c|c|c|c|}
\hline & \multicolumn{2}{|c|}{ Use a BPMM Model } \\
\hline & & No & Yes \\
\hline \multirow{2}{*}{$\begin{array}{l}\text { Have KM strategy or } \\
\text { plan within a year }\end{array}$} & No & 9 & 2 \\
\hline & Yes & 17 & 22 \\
\hline \multicolumn{2}{|l|}{ Total } & 26 & 24 \\
\hline
\end{tabular}

